\title{
APRESENTAÇÃo
}

\author{
PRESENTATION
}

\section{Linguagem e trabalho: diálogos entre estudos discursivos e ergológicos}

\section{Langage et travail: dialogues entre études discursives et ergologiques}

$A^{\text {pes }}$ proposta de colocar em diálogo estudos discursivos e ergológicos remonta à década de 1980, quando na França começaram a ser desenvolvidas pesquisas pluridisciplinares tendo como objeto de estudo a atividade de trabalho ${ }^{1}$. No campo da linguagem, destacou-se, nesse contexto, a produção do linguista Daniel Faïta que, em interação com a perspectiva ergológica, na época desenvolvida no âmbito do grupo Analyse Pluridisciplinaire des Situations du Travail (APST), produziu, dentre outros, o texto Falar do trabalho, trabalhar a fala, publicado originalmente, em 1985, no livro L'homme producteur. Autour des mutations $d u$ travail et des savoirs, obra coorganizada com Yves Schwartz ${ }^{2}$.

No Brasil, essa interface começou a ser desenvolvida formalmente, na segunda metade da década de 1990, em especial com o acordo bilateral, Brasil/França, Capes-Cofecub, que envolveu, do lado brasileiro, a PUC-SP, a PUC-Rio e a UFRJ, e, do lado francês, a Université de Provence-Aix-Marseille e a Université de Rouen ${ }^{3}$. O resultado desse convênio está parcialmente consubstanciado em duas obras, uma publicada na França (RICHARD-ZAPPELLA, 1999) e outra no

\footnotetext{
1 Neste período, o grupo Langage \& Travail, criado em 1986, reunindo linguistas, sociólogos, psicólogos, ergonomistas etc., desenvolveu importantes pesquisas, muitas da quais publicadas em livros, como Parole au travail (BOUTET, 1995), La transgression des régles au travail (GIRIN; GROSJEAN, 1995), Le monde du travail (KERGOAT; BOUTET; JACOT; LINHART, 1998) e Langage et Travail (BORZEIX; FRAENKAEL, 2001).

2 O texto de Faïta está disponível no livro Análise dialógica da atividade profissional (FAÏTA, 2005a). Depois da APST, Faïta passou a fazer parte do grupo Ergonomie de l'Activité des Professionnels de l'Éducation (ERGAPE), no Institut Universitaire de Formation des Maîtres de l'Académie d'Aix-Marseille. Além desses grupos, desde o final da década de 1990, Faïta participa da equipe da Clinique de l'Activité, no Conservatoire National des Arts et Métiers (CNAM), em Paris.

3 Também foram formalizados, conforme Souza-e-Silva (2002b), os acordos Brasil/Inglaterra, entre a PUC-SP e a Liverpool University, e Brasil/Portugal, entre PUC-SP, PUC-Rio e a Universidade de Lisboa.
}

Brasil (SOUZA-E-SILVA; FAÏTA, 2002a). Nesse cenário, destaca-se a contribuição do Programa de Estudos Pós-Graduados em Linguística Aplicada e Estudos da Linguagem (PEPG-LAEL), notadamente do Grupo Atelier Linguagem e Trabalho (PUC-SP/CNPq), coordenado pela professora Maria Cecília Pérez de Souza-e-Silva, que desenvolveu um núcleo de pesquisa e formação, voltado para a linha de pesquisa Linguagem e Trabalho, com especial destaque para a interface entre os estudos discursivos, em suas diferentes vertentes enunciativas, e os estudos do trabalho, como os desenvolvidos pela Ergologia, Clínica da Atividade e Ergonomia da Atividade. Com a formação de um número significativo de mestres e doutores, pesquisas sobre essa interface passaram a ser desenvolvidas em diferentes universidades brasileiras que, consequentemente, se tornaram também centros de referência na área, como UERJ, UNIRIO, PUCRS e UFF.

Em decorrência também do interesse de investigação dos integrantes do Grupo Atelier e das redes de pesquisa instauradas, foi criado em 2006 o GT Linguagem, Enunciação e Trabalho, junto à ANPOLL (Associação Nacional de Pós-Graduação e Pesquisa em Letras e Linguística), com o intuito de reunir pesquisadores voltados para as seguintes linhas de pesquisa: (i) estudo das práticas de linguagem que se fazem presentes no interior de uma situação de trabalho; (ii) estudo dos discursos produzidos por diferentes interlocutores nos quais o tema trabalho é relevante; e (iii) estudo de práticas discursivas de variadas esferas de atividade (midiática, cultural, acadêmica etc.). Atualmente o GT conta com participantes de variadas universidades do Brasil, como PUC-SP, UERJ, UNIRIO, PUCRS, UFF, UNISINOS, UPF, UTFPR, PUC-Rio e UFPA, alguns dos quais submeteram trabalhos para esta publicação.

Considerando o exposto e a proposta deste número da Letras de Hoje de publicar textos originais que tenham 
como foco a relação linguagem e trabalho, em especial que contemplem a interface entre os estudos discursivos e a abordagem ergológica, apresentamos uma breve reflexão das contribuições da abordagem ergológica seguida de uma das vertentes dos estudos discursivos que temos mobilizado nas nossas investigações - a perspectiva dialógica bakhtiniana. Para finalizar, apresentamos, de forma sucinta, os artigos que compõem o presente número da revista Letras de Hoje.

A abordagem ergológica tem como objeto de estudo a atividade de trabalho ou, mais especificamente, a atividade humana de trabalho em sua complexidade. No entendimento de Schwartz (2011, p.20), um dos principais estudiosos da Ergologia, o trabalho "é uma realidade enigmática", que "escapa a toda definição simples e unívoca".

$\mathrm{Na}$ Introdução à edição brasileira de Trabalho \& Ergologia: conversas sobre a atividade humana, Athayde e Brito (2010, p.7) questionam: "Seria [a Ergologia] uma nova disciplina a concorrer no mercado de especialistas da atividade humana, do trabalho?" Respondendo negativamente à questão, observam que se trata de um tipo de "in-disciplina", explicada por uma estranheza, que considera "toda atividade, inclusive a atividade de trabalho matriz de variabilidade", uma vez que "é atravessada pelo inédito, pelo evento, pela complexidade" (p.11). É nessa direção que "buscamos pensar no trabalho, ou mais precisamente na atividade de trabalho, como um lugar fluido, precisamente 'indisciplinar', que necessita da recorrência a outras áreas do conhecimento além da de origem do pesquisador" (DI FANTI, 2012, p. 310). É nesses termos também que Trinquet (2010, p. 94), baseado em Schwartz, entende que a Ergologia pressupõe uma investigação pluridisciplinar, em função de a atividade de trabalho ser muito complexa. Destaca que todas as disciplinas "são necessárias, embora nenhuma seja suficiente"

Em sua própria constituição, a Ergologia teve três grandes influências: a experiência de pesquisa-intervenção do médico e psicólogo italiano Ivar Oddone, as reflexões da Ergonomia da Atividade, em especial de Alain Wisner, e a Filosofia de George Canguilhem (SCHWARTZ, 2006, p. 459, 460). A partir de Oddone, veio a inspiração de estreitar a relação da academia com o mundo do trabalho, já que o médico italiano, criando uma "comunidade científica ampliada", buscou aproximar,

\footnotetext{
4 Dentre as disciplinas convocadas pela abordagem ergológica, destacamos: filosofia, ergonomia da atividade, linguística, psicologia do trabalho, sociologia etc.

5 Essa experiência está na base da formação do grupo APST na Université de Provence (Aix-Marseille I).

6 Parte dessas reflexões foram desenvolvidas no artigo Linguagem e trabalho: diálogo entre a translinguística e a ergologia (DI FANTI, 2012).
}

em um contexto histórico singular, os operários da Fiat italiana, os integrantes dos sindicatos e o pessoal da Universidade. Essa experiência tomou forma no início dos anos 80, quando o grupo, formado pelo filósofo Yves Schwartz, o linguista Daniel Faïta e o sociólogo Bernard Vuillon, propondo a aproximação da academia ao mundo do trabalho, criou, em 1983, um estágio de formação continuada com trabalhadores da região de Provence na França ${ }^{5}$. Tal estágio permitiu uma troca entre os saberes acadêmicos e os saberes do mundo do trabalho (SCHWARTZ, 2006).

No que concerne à influência da Ergonomia da Atividade, a Ergologia baseou-se nas reflexões sobre a atividade humana de trabalho, segundo a qual há uma distância entre o prescrito e o real, o que se contrapõe à visão positivista do regime taylorista, que considerava o trabalhador um mero executor das prescrições. Essa visão foi ampliada com a influência da filosofia da vida de George Canguilhem, especialmente com o conceito de atividade industriosa, que envolve sempre um debate de normas, o que remete à relação entre o social e o singular, à possibilidade de escolhas, ao debate de valores ${ }^{6}$.

Uma das contribuições da Ergologia é a proposição de um dispositivo de análise baseado em três polos: (i) o polo dos saberes constituidos, formado por conceitos, competências e conhecimentos acadêmicos; (ii) o polo dos saberes investidos na atividade, que resgata a experiência prática e recriadora de saberes via debate de normas; e (iii) o polo das exigências ergológicas, constituído por exigência ética e meios para a busca de soluções. A postura de associar os saberes constituídos e investidos "consiste em uma atitude deontológica e ética, mas, se trata, sobretudo, de uma postura cientifica", que, ao resgatar características da atividade concreta, fomenta a busca de respostas para problemas observados (TRINQUET, 2010, p. 100).

Uma preocupação da Ergologia também é analisar a atividade de trabalho na intrínseca relação entre contexto e vida particular. Fazendo remissão às reflexões do ergonomista François Daniellou sobre a relação entre trama e urdidura, Duraffourg (2010, p.62) observa que aquele que se interessa pelo trabalho se encontra efetivamente num cruzamento. De um lado, encontra-se a trama, conjunto de procedimentos e meios, resultado de experiências capitalizadas em níveis econômicos, jurídicos, organizacionais etc., que constituem as situações de trabalho. De outro, está a urdidura, que é o investimento nessas situações de indivíduos singulares, com histórias e experiências pessoais, "seus corpos e sua subjetividade, seus desejos e suas expectativas [..]" (p.62). Tais reflexões põem em destaque a importância de o pesquisador interessar-se pela "dialética fundamental entre o singular e o geral", pois o não reconhecimento dessa 
dialética leva ao que o ergonomista da atividade chama de "verdadeiro massacre". De acordo com Duraffourg, o "massacre" acontece em duas direções: quando "nos atemos de forma abstrata aos fenômenos gerais", que escapam completamente ao concreto do trabalho (p.62), e quando nos atemos estritamente ao singular, ao nível vivido, sem ligação com o contexto.

Para Athayde e Brito (2010, p.10), é importante considerar que, "ao contrário de buscar respostas gerais sobre o que ocorre com o trabalho, por meio de fórmulas [...], a Ergologia propõe uma análise 'situada', apostando na potência humana de compreender-transformar o que está em jogo [...]". Busca-se a (re)invenção, criação de "novas condições e um novo meio pertinente a si e à situação". A abordagem ergológica, na visão de Schwartz (2010a, p. 37), "constitui-se como um projeto de melhor conhecer e, sobretudo, de melhor intervir sobre as situações de trabalho para transformá-las".

Há de se considerar, no entanto, que o trabalho está em permanente modificação, e talvez aí esteja o grande desafio: compreendê-lo na mudança. Esse dinamismo causa um desconforto intelectual no pesquisador, pois não há um modelo de interpretação que sirva para todas as variabilidades. "É preciso estar atento à atividade das pessoas que trabalham" (SCHWARTZ, 2010b, p. 27, 28):

Se não se faz um esforço de ir ver de perto como cada um não apenas "se submete" - entre aspas - mas vive e tenta recriar sua situação de trabalho, se não se faz esse esforço, então interpreta-se, julga-se e diagnostica-se no lugar das próprias pessoas e isso não pode produzir resultados positivos. (p.26)

A inquietação do pesquisador faz-se necessária diante da atividade de trabalho, já que há um permanente debate de normas, que põe em jogo a dialética entre as normas antecedentes e as renormalizações, e a dialética entre o uso de si por si e o uso de si pelos outros (SCHWARTZ, 2010b). Para Duraffourg (2010, p. 70), deve-se atentar para a diferença entre análise da atividade de trabalho e análise do trabalho, observando que "a análise do trabalho é a análise da situação de trabalho, na qual a atividade se inscreve". Uma análise está atrelada à outra assim como valores são engajados no trabalho, em diferentes níveis, atravessando o micro da atividade e a sociedade em sentido mais amplo.

Ao se considerar o trabalho como atividade, reconhece-se o caráter enigmático de quem trabalha, uma vez que "a vida ultrapassa os conceitos, os procedimentos" (SCHWARTZ, 2010c, p. 137). Sendo "o meio sempre infiel”, seguindo Canguilhem, não haverá repetição de "um dia para o outro, ou de uma situação de trabalho a outra" (2010d, p. 189); o vazio das normas impõe o arriscar-se no trabalho, o fazer uso de si. Envolvido nas dramáticas dos usos de si, Schwartz (p. 196) propõe que se considere o corpo-si, "entidade enigmática que resiste às tentativas de ser objetivado":

[...] coloca-se o dedo sobre "alguma coisa" que nos ultrapassa a todos, na medida em que isso nos remete às profundezas do que somos - a essa "alguma coisa" que é, digamos [...], biológica, mas atravessada de história. Ou seja, nós trabalhamos nosso corpo, nós o trabalhamos permanentemente pela nossa experiência de vida - e portanto por nossas paixões, por nossos desejos, por nossas experiências [...] Trata-se do histórico, mas do histórico funcionando em alquimias que vão além de nós: e que vão além, tanto de quem lhe mostra o espelho, quanto de quem está diante dele. (p. 197)

O corpo-si, no dizer de Schwartz, "é um elemento de transgressão" (p.200), já que a atividade "obriga a transgredir", a lutar para restituir espaço e dimensão proativa e criadora.

No que tange à dimensão da linguagem nas análises do trabalho, consideramos, como entende Faïta (2010, p. 180), que a linguagem é inseparável das atividades, ou ainda "a linguagem é uma atividade", que "permite agir sobre o outro e sobre nós mesmos", permite transformarnos: "É por meio da linguagem que cada um de nós vai, por exemplo, mobilizar ou remobilizar, segundo as cirscunstâncias, os saberes que detém, quer se trate de saberes teóricos ou empíricos".

Entender a linguagem como atividade e ainda mais como indissociável das ativididades de trabalho remonta a reflexões que temos desenvolvido, que ressaltam a importância da análise da linguagem para a compreensão, ainda que parcial, da atividade laboral (DI FANTI, 2004, 2012, 2013). ${ }^{7}$ Nesse âmbito, temos dialogado com abordagens que preconizam a análise de enunciados concretos, situados sócio-historicamente, em diferentes materializações verbais e não verbais, cujas vozes sociais reverberam complexas relações de sentidos.

Nessa esteira, a concepção de ato ético, responsável e responsivo, desenvolvida por Bakhtin (2010a), vem ao encontro da perspectiva adotada na interface estudos discursivos e ergológicos, especialmente no que tange à observação de que é pelo ato que a perniciosa divisão entre a cultura (mais ampla) e a vida pode ser superada. Ou seja, é na inteireza do ato que se observam forma e conteúdo, teoria e prática, processo e produto, aspectos gerais e singulares, o domínio da cultura e a irrepetibilidade da vida. Bakhtin antecipa, em seu texto sobre o ato, como

\footnotetext{
Nouroudine (2002) e Souza-e-Silva (2005) destacam a importância do papel da linguagem na análise de práticas profissionais.
} 
destaca Faraco (2009, p. 23-24), a linguagem "como atividade (e não como sistema) e o enunciado como um ato singular, irrepetível, concretamente situado e emergindo de uma atitude ativamente responsiva" 8 . Tal abordagem pressupõe a permanente inter-relação consigo próprio e com o outro, a alteridade constitutiva, responsável pela circulação e produção de sentidos.

As relações dialógicas, de acordo com Bakhtin (2010b, p. 209), são possíveis "a qualquer parte significante do enunciado, inclusive a uma palavra isolada", desde que materializada como signo ideológico. Para Bakhtin/ Volochinov (2006), a palavra é, por excelência, um signo ideológico, que não só reflete mas também refrata uma dada realidade, já que possui natureza dinâmica e seus acentos valorativos revelam diferentes e tensas relações de sentido entre vozes discursivas e signos ideológicos, oriundos de variadas direções.

A palavra, segundo Volochínov (2011, p. 154), "surge da situação extraverbal da vida e conserva com ela o vínculo mais estreito", o que significa que a palavra não pode ser dissociada da vida. Ressalta-se, no entanto, que a situação extraverbal não atua como uma força mecânica externa, mas sim como parte integrante, necessária para a composição semântica. A enunciação "nasce, vive e morre no processo de interação social dos participantes":

Ao arrancar a enunciação deste chão real que a alimenta, perdemos a chave que abre o acesso de compreensão tanto de sua forma quanto de seu sentido; em nossas mãos ficam ou uma moldura linguística abstrata, ou um esquema abstrato de sentido [...]. (VOLOCHÍNOV, 2011, p. 165)

Disso resulta o entendimento de que não há coincidência entre sentido e estrutura puramente verbal, já que a constituição dos sentidos pressupõe um jogo entre o dito e o não dito, entre a palavra e a situação extraverbal, entre valorações sociais. A entonação, ao situar-se na fronteira entre a vida e a parte verbal da enunciação, "parece bombear a energia de uma situação vital à palavra", atribuindo "a tudo o que é linguisticamente estável uma dinamicidade histórica viva e uma unicidade irrepetível" (VOLOCHÍNOV, 2011, p. 165).

Nesse contexto, entendemos que "a aproximação entre as abordagens dialógica e ergológica para tratar da relação entre linguagem e trabalho mostra-se bastante produtiva ao se considerar que ambas têm como centro de reflexão a atividade humana, seja na dimensão linguageira, seja na laboral" (DI FANTI, 2012, p. 325; 2013). Sendo as duas dimensões complexas, tanto pela constituição dialógica, quanto pela enigmática, necessita-se de práticas

\footnotetext{
8 Sobre o ato ético bakhtiniano, consultar também Sobral (2005) e Amorim (2009).
}

de pesquisa que considerem a vivacidade do objeto, seu caráter de evento, na intrínseca relação de alteridade em diferentes dimensões. Destaca-se, assim, a importância de reconhecer a dialética constitutiva do enunciado, tecida pela dinâmica coexistência de diferenças, que faz reverberar valores, posições ideológicas e saberes de uma dada atividade.

Este Dossiê da Letras de Hoje, propondo-se a publicar textos que têm como foco a relação linguagem e trabalho ou que aprofundem uma das dimensões propostas, cujas reflexões possam contribuir ou apresentar potencialidades de contribuições para o tema central, selecionou para publicação 11 artigos. O primeiro, Motivações do conceito de corpo-si: corpo-si, atividade, experiência, de Yves Schwartz, propõe-se a explicar como o conceito de atividade de trabalho, considerado como uso de si por si e pelos outros, passou a uma "dramática do uso de um corpo-si”. Discute também como o corpo-si acumula experiências e saberes extremamente diversos, em especial na relação com a linguagem, o que capacita ao enfrentamento da dinamicidade constante da vida.

Christine Castejon, em L'ergonome et l'agent. Quand la perspective anthropologique s'invite, apresenta seu entendimento de corpo-si a partir da elaboração de Yves Schwartz. Tendo por base a obra de Meschonnic, a autora, dispensando uma simples abordagem comunicativa, propõe pôr em relação a linguagem e o corpo-si.

Em A interface estudos discursivos e estudos ergológicos, Maria Cecília Pérez de Souza-e-Silva busca explicitar caminhos teórico-metodológicos seguidos no estudo das relações entre abordagens discursivas e ergológicas. Para a autora, ambas as abordagens encontram abrigo no paradigma indiciário, que supõe a existência, ao mesmo tempo, de um rigor flexível e elástico. Souza-e-Silva ancora sua reflexão sobre linguagem nas contribuições do analista do discurso Dominique Maingueneau, cujo aporte enunciativodiscursivo também fundamenta, em termos teóricos, importantes pesquisas apresentadas neste número. O foco da reflexão tem como ponto de partida Gênese dos discursos (MAINGUENEAU, 2005), sua obra fundadora, cuja originalidade pode ser vista, principalmente, pela implementação do princípio de que o interdiscurso precede o discurso e pelo tratamento do discurso a partir de um sistema de coerções globais. Conta, ainda, com contribuições advindas de Cenas da Enunciação (idem, 2008) e Doze conceitos em Análise do Discurso (idem, 2010). O primeiro tem como fio condutor o conceito de cena de enunciação, presente no estudo de vários tipos de textos ou discursos; o segundo não se desenvolve a partir de uma noção central, mas sim caracteriza-se pela articulação dos diferentes artigos em torno de conceitos em Análise do Discurso. 
Ana Raquel Motta, em Muito além da cigarra e da formiga, analisa como experiências humanas desconstroem o discurso da "Cigarra e da Formiga". A partir da análise de um vídeo sobre o trabalho em uma Casa de Farinha, na Bahia, chega à conclusão de que, em mutirões em que se trabalha cantando, o corpo-si integra aspectos da identidade, do cumprimento da tarefa e da memória coletiva do grupo.

Em Argumentos para uma abordagem discursiva das práticas de linguagem no trabalho, Décio Rocha e Bruno Deusdará, respondendo a uma demanda de pesquisadores da área da saúde, avaliam possibilidades e limites de uma abordagem conteudista das práticas de linguagem à luz de alguns dos pressupostos da abordagem discursiva desenvolvida por Maingueneau. Concluem que usos de determinados dispositivos metodológicos orientam a imagem de mundo que se pretende legitimar, a qual privilegia formas constituídas, não permitindo embates de forças e, consequentemente, a produção de novos modos de vida.

Del Carmen Daher, no artigo Um exame de prática discursiva do trabalho de seleção de professores de línguas estrangeiras para o sistema público de ensino básico, apresenta considerações sobre a prática do concurso público que seleciona professores de línguas estrangeiras para o ensino básico. Tendo como referencial teórico uma perspectiva discursiva de base enunciativa e as contribuições advindas da abordagem ergológica, as reflexões buscam "contribuir com discussões sobre o campo profissional do linguista e suas possibilidades de intervenção em questões sociais, em particular no que concerne a impasses e renormalizações vinculadas à realização desse trabalho".

Em Práticas discursivas delimitadoras de conteúdos: estudo de ementas da formação profissional de professor de línguas, Vera Lucia de Albuquerque Sant'Anna, a partir de uma concepção discursiva de linguagem em busca de um diálogo com a perspectiva ergológica de estudos sobre o trabalho, reflete sobre tendências à aproximação e afastamento da situação de trabalho do professor de ensino superior. A análise das ementas aponta traços discursivos que remontam a memórias que alimentam valores sobre o ensino de língua, língua, e, como consequência, papel do professor.

No artigo Práticas linguageiras e ethos discursivo: vozes de sujeitos "que falam" sobre o trabalho, Ernani Cesar de Freitas, Itatiane Chiaradia e Débora Facin apresentam uma análise da cenografia e do ethos construídos em dizeres de sujeitos participantes de uma associação de catadores de material reciclável no RS. Para atingir o objetivo proposto, os autores também analisam o Regimento e o Estatuto da referida associação.

Shirlei Marly Alves, em A ativid@de de tutores na Educação a Distância: um olhar ergológico para o prescrito e o vivido nos ambientes virtuais de aprendizagem, apresenta uma proposta de estudo sobre a atividade de tutoria on-line em cursos de Educação a Distância. Tendo como base a concepção ergológica de trabalho, a autora postula que o estudo científico a partir da episteme ergológica contribui para uma compreensão que vai além do que se prescreve para a tarefa do tutor.

$\mathrm{O}$ artigo Enunciação e trabalho: a integração do homem à sua cultura profissional, de Carmem Luci da Costa Silva, Lia Emília Cremonese e Simone de Lima Silveira Barros, objetiva "entender como um autor da área de ciências da saúde enuncia a sua posição de locutor para constituir o outro em um artigo de opinião". Como referencial teórico, as autoras buscam apoio na noção de linguagem de Émile Benveniste e na perspectiva ergológica de Yves Schwartz.

Em A Linguagem como trabalho: reflexões iniciais sobre a alienação linguística, Vitor Vieira Ferreira e Luiz Barros Montez situam as produções linguísticas na categoria de trabalho, seguindo os escritos de Karl Marx. É enfatizada a relevância dos estudos do discurso que analisam estratégias e realizações materiais, engendradas em práticas sociais, legitimando e reproduzindo distintas formas de dominação.

Para finalizar esta Apresentação, não poderíamos deixar de registrar os sinceros agradecimentos aos que colaboraram para esta publicação. Destaco, dentre outros, os professores-pesquisadores Maria Cecília Pérez de Souza-e-Silva e Yves Schwartz, que participaram da organização deste Dossiê; os autores, que enviaram seus trabalhos para publicação; os pareceristas, que contribuíram com seu importante trabalho para a qualificação dos artigos publicados; e a equipe editorial da Letras de Hoje, que deu todo o apoio necessário para a viabilização da publicação. Fica o nosso convite aos leitores para percorrerem os caminhos aqui propostos, na expectativa de não só buscar respostas, mas também apresentar questionamentos às ideias levantadas, de modo a fazer avançar as pesquisas sobre linguagem e trabalho e, particularmente, sobre estudos discursivos e ergológicos.

Maria da Glória Corrêa di Fanti Organizadora 


\section{Referências}

AMORIM, M. Para uma filosofia do ato: "válido e inserido no contexto". In: BRAIT, B. (Org.). Bakhtin: dialogismo e polifonia. São Paulo: Contexto, 2009.

ATAHYDE, M.; BRITO, J. Introdução à edição brasileira: Ergologia e um livro-ferramenta, uma tecelagem que se propaga. In: SCHWARTZ, Y.; DURRIVE, L. (Org.). Trabalho \& ergologia: conversas sobre a atividade humana. Niterói: EdUFF, 2010.

BAKHTIN, M. Para uma filosofia do ato responsável. Tradução de Valdemir Miotello e Carlos Alberto Faraco. São Carlos, SP: Pedro \& João Editores, 2010a.

BAKHTIN, M. Problemas da poética de Dostoiévski (1929). 5.ed. revista. Tradução Paulo Bezerra. Rio de Janeiro: Forense Universitária, 2010b.

BAKHTIN, M. [VOLOCHINOV, V.]. Marxismo e filosofia da linguagem: problemas fundamentais do método sociológico na ciência da linguagem (1929). Tradução Michel Lahud e Yara Vieira. São Paulo: Hucitec, 2006.

BORZEIX, A.; FRAENKAEL, B. (Org.). Langage et travail: communication, cognition, action. Paris: CNRS, 2001.

BOUTET, J. (Org.). Parole au travail. Paris: L'Harmattan, 1995.

DI FANTI, M. G. C. Discurso, trabalho \& dialogismo: a atividade jurídica e o conflito trabalhador/patrão. 2004. $385 f$ f. Tese (Doutorado em Linguística Aplicada e Estudos da Linguagem) - LAEL, Pontifícia Universidade Católica de São Paulo, São Paulo, 2004.

DI FANTI, M. G. C. Linguagem e trabalho: diálogo entre a translinguística e a ergologia. Desenredo (PPGL/UPF), Passo Fundo, v. 8, 2012.

DI FANTI, M. G. C. Perspective dialogique et approche ergologique: (inter)faces de la relation langage-travail. Ergologia, Revue de la Société Internationale d'Ergologie, Aix-en-Provence, n. 9, 2013.

DURAFFOURG, J. O trabalho e o ponto de vista da atividade. Uma conversa entre Jacques Duraffourg, Marcelle Duc e Louis Durrive. Tradução Ana Luiza Telles e Eliza Echternacht. In: SCHWARTZ, Y.; DURRIVE, L. (Org.). Trabalho \& ergologia: conversas sobre a atividade humana. Niterói: EdUFF, 2010.

FAÏTA, D. Análise dialógica da atividade profissional. Organização e tradução Maria da Glória di Fanti, Maristela França e Marcos Vieira. Rio de Janeiro: Imprinta, 2005a.

FAÏTA, D. Falar do trabalho, trabalhar a fala. Tradução Maristela Botelho França. In: Análise dialógica da atividade profissional. Rio de Janeiro: Imprinta, 2005b.

FAÏTA, D. A linguagem como atividade. Uma conversa entre Daniel Faïta, Christine Noël e Louis Durrive. Tradução Maria da Glória di Fanti e Maristela França. In: SCHWARTZ, Y.; DURRIVE, L. (Org.). Trabalho \& ergologia: conversas sobre a atividade humana. Niterói: EdUFF, 2010.

FARACO, C.A. Linguagem \& diálogo: as ideias linguísticas do círculo de Bakhtin. São Paulo: Parábola, 2009.

FARACO, C.A. Um posfácio meio impertinente. In: BAKHTIN, M. Para uma filosofia do ato responsável (1920-1924). São Carlos: Pedro \& João Editores, 2010.

KERGOAT, J.; BOUTET, J.; JACOT, H.; LINHART, D. (Org.). Le monde du travail. Paris: La Découvert, 1998.
MAINGUENEAU, D. Gênese dos discursos (1984). Tradução Sírio Possenti. Curitiba: Criar Edições, 2005.

MAINGUENEAU, D. Cenas da enunciação. Organização de Sírio Possenti e Maria Cecília Pérez de Souza-e-Silva. São Paulo: Parábola Editorial, 2008.

MAINGUENEAU, D. Doze conceitos em Análise do Discurso. Organização de Sírio Possenti e Maria Cecília Pérez de Souzae-Silva. São Paulo: Parábola, 2010.

NOUROUDINE, A. A linguagem: dispositivo revelador da complexidade do trabalho. In: SOUZA-E-SILVA, M.C.; FAÏTA, D. (Org.). Linguagem e trabalho: construção de objetos de análise no Brasil e na França. Tradução Ines Polegatto e Décio Rocha. São Paulo: Cortez, 2002.

RICHARD-ZAPPELLA, J. (Org.). Espaces de travail, espaces de parole. Rouen: Publications de l'Université de Rouen Collection DYALANG - CNRS, 1999.

SCHWARTZ, Y. Entrevista. Revista trabalho, educação e saúde. Rio de Janeiro: Fundação Oswaldo Cruz, v. 4, n. 2, p. 457-466, 2006.

SCHWARTZ, Y. Reflexão em torno de um exemplo de trabalho operário. Tradução Jussara Brito e Marcus Vinícius Pereira. In: SCHWARTZ, Y.; DURRIVE, L. (Org.). Trabalho \& ergologia: conversas sobre a atividade humana. Niterói: EdUFF, 2010a.

SCHWARTZ, Y. Trabalho e ergologia. Uma conversa entre Yves Schwartz, Marcelle Duc e Louis Durrive. Tradução Jussara Brito e Milton Athayde. In: SCHWARTZ, Y.; DURRIVE, L. (Org.). Trabalho \& ergologia: conversas sobre a atividade humana. Niterói: EdUFF, 2010b.

SCHWARTZ, Y. A linguagem em trabalho. Tradução Maria Cecília Pérez de Souza-e-Silva e Décio Rocha. In: SCHWARTZ, Y.; DURRIVE, L. (Org.). Trabalho \& ergologia: conversas sobre a atividade humana. Niterói: EdUFF, 2010c.

SCHWARTZ, Y. Trabalho e uso de si. Tradução Maria Elisabeth B. de Barros. In: SCHWARTZ, Y; DURRIVE, L. (Org.). Trabalho \& ergologia: conversas sobre a atividade humana. Niterói: EdUFF, 2010d.

SCHWARTZ, Y. Conceituando o trabalho, o visível e o invisível. Revista trabalho, educação e saúde. Rio de Janeiro: Fundação Oswaldo Cruz, v. 9, supl. 1, p. 19-45, 2011.

SOBRAL, A. Ato/atividade e evento. In: BRAIT, B. (Org.). Bakhtin: conceitos-chave. São Paulo: Contexto, 2005.

SOUZA-E-SILVA, M. C.P.; FAÏTA, D. (Org.). Linguagem e trabalho: construção de objetos de análise no Brasil e na França. São Paulo: Cortez, 2002a.

SOUZA-E-SILVA, M. C.P.. A dimensão linguageira em situações de trabalho. In: SOUZA-E-SILVA, M.C.P.; FAÏTA, D. (Org.). Linguagem e trabalho: construção de objetos de análise no Brasil e na França. São Paulo: Cortez, 2002b.

SOUZA-E-SILVA, M.C.P. O papel da linguagem na análise de práticas profissionais. Projeto de pesquisa, PUC/SP, 2005.

TRINQUET, P. Trabalho e educação: o método ergológico. Revista Histedbr, número especial, 2010.

VOLOCHÍNOV, V. A palavra na vida e na poesia. Introdução ao problema da poética sociológica (1926). In: BAKHTIN, M. Palavra própria e palavra outra na sintaxe da enunciação. São Carlos: Pedro \& João Editores, 2011. 